\title{
REDUZINDO A FUTURA LACUNA DE COMPETÊNCIAS NA AMÉRICA LATINA E NO CARIBE POR MEIO DE INOVAÇÕES EM EDUCAÇÃO APLICADA
}

\section{Rodrigo Filgueira*}

*Especialista em Aprendizagem Assistida por Tecnologias Avançadas pelo Centro Interamericano para o Desenvolvimento do Conhecimento na Formação Profissional, da Organização Internacional do Trabalho (OIT/Cinterfor). Engenheiro em Computação pela Faculdade de Engenharia da Universidade da República do Uruguai. Trabalha há vinte anos em formação profissional, tecnologias aplicadas à formação e inovação pedagógica. Atualmente, realiza pesquisas e oferece suporte técnico às instituições de formação profissional na utilização de novas metodologias e tecnologias para o treinamento baseado em modelos centrados no aluno. Montevidéu, Uruguai. E-mail: filgueira@ilo.org

Recebido para publicação em 24.9.2018

Aprovado em 14.11.2018

\section{Resumo}

O artigo classifica as competências necessárias para o futuro do trabalho identificadas em pesquisas recentes, lideradas pela Organização Internacional do Trabalho (OIT), pelo Centro Interamericano para o Desenvolvimento do Conhecimento na Formação Profissional (Cinterfor) e por outras instituições. Em seguida, recomenda que a lacuna de competências no mercado de trabalho da América Latina e no Caribe seja reduzida pela inovação das instituições de Educação Profissional. Com esse empenho, propõe que o aprendizado baseado em problemas e pedagogias de aprendizagem de qualidade sejam métodos fundamentais de ensino para o desempenho do aluno em competências socioemocionais.

Palavras-chave: Aprendizagem de qualidade. Formação e treinamento profissional. Aprendizagem Baseada em Projetos.

\section{Introdução}

O mercado de trabalho do futuro, caracterizado pelo conceito de futuro do trabalho, exigirá competências que os alunos do sistema de Educação Profissional (EP) atualmente não estão desenvolvendo.

$\mathrm{O}$ argumento neste documento mostra que o futuro do trabalho relacionado com a lacuna de competências é o mesmo que atualmente afeta fortemente a região da América Latina e do Caribe (ALC), especialmente quando se refere às competências socioemocionais. Dada a semelhança entre os dois conjuntos de competências, aqueles adaptados pelos sistemas de EP em outras regiões podem divulgar as estratégias da região que visam ao estreitamento da lacuna de competências.

Contudo, a resistência às mudanças, assim como o cenário de instabilidades políticas e econômicas na região, soma-se nos motivos para as inovações, e os riscos que as mesmas acarretam, demorarem tanto a ser testados e integrados. 
Não obstante, é verdade que, durante os últimos trinta anos, quase todos os sistemas EP na região passaram por modificações de menor ou maior importância. Entre o fim dos anos 1990 e 2010, as Instituições de Educação Profissional (IEPs) adotaram abordagens baseadas em competências e treinamento de garantia de qualidade, que exigiam grandes investimentos e riscos. Muitas instituições também começaram a prover suporte para a pesquisa aplicada, centros de inovações e abordagens inovadoras de aprendizagem.

Na verdade, desde o fim de 2010, algumas instituições filiadas ao Cinterfor - uma divisão técnica da Organização Internacional do Trabalho (OIT) - vêm introduzindo novas estratégias para atender às necessidades do mercado de trabalho. Tanto no Brasil como na Colômbia, as IEPs têm incorporado novas abordagens de aprendizado ao currículo, com níveis variáveis de sucesso em termos de implementação efetiva. Em El Salvador, o interesse do setor plástico está gerando demanda por aprendizagens/abordagens duplas. Isso também se verifica na República Dominicana em relação a outros setores e empreendimentos.

Embora reformas completas provavelmente não sejam vistas no curto prazo, há muitos programas de EP já testando estas duas inovações relevantes para o futuro do trabalho e o atual mercado de trabalho na ALC, a saber: Programa de Aprendizagem (PA) e Aprendizagem Baseada em Projetos (ABP).

Sob esta perspectiva, as iniciativas que as IEPs estão implementando devem provar que esses métodos são mais eficazes para o desenvolvimento de competências socioemocionais; demonstrar que essas duas abordagens são complementares em termos metodológicos; e provar que os sistemas EP estão sob a expectativa de que cumpram o prometido ao futuro do trabalho, ambos precisam ser aplicados.

\section{Contexto}

\subsection{Lacuna de competências}

0 mercado de trabalho na ALC apresenta as lacunas mais amplas entre oferta e procura de competências
Economias na região ALC têm sofrido com a baixa e estagnada produtividade já por algum tempo (ECLAC, 2012). De acordo com a Organização para a Cooperação e Desenvolvimento Econômico (OCDE), todos os agentes participantes reconhecem que a força de trabalho, muitas vezes, não dispõe das competências adequadas, um argumento particularmente apoiado por empregadores e visto por eles como causa relevante para os infortúnios de produtividade da região (MELGUIZO; PEREA, 2016).

O mesmo relatório da OCDE indica que, de todas as regiões econômicas do mundo, o mercado de trabalho na ALC apresenta as lacunas mais amplas entre oferta e procura de competências. Essa conclusão é apoiada não só por relatos de outros estrategistas - Economist Intelligence Unit (EIU); empresas de consultoria (McKinsey, ManpowerGroup); e bancos multilaterais 
de desenvolvimento, como o Banco Interamericano de Desenvolvimento (BID) e o Banco de Desenvolvimento da América Latina (CAF) -, mas também por pesquisas realizadas por governos e instituições públicas da região (VARGAS ZUÑIGA; CARZOGLIO, 2017).

Dado que a região é tradicionalmente importadora de tecnologia e processos de produção, pode-se ficar tentado a acreditar que essa lacuna é causada principalmente por competências relacionadas a maquinário, materiais ou processos específicos. Embora isso ainda seja verdade, não alcança uma grande parte do problema.

O conjunto de competências em demanda atualmente, que os trabalhadores parecem não ter, agora inclui competências socioemocionais, e elas são tão relevantes quanto o conjunto de conhecimentos técnicos. Os estudos realizados pelo Instituto Nacional de Aprendizagem (INA), na Costa Rica, e pelo Chilevalora, no Chile (CALVO SANTANA; COTO CALDERÓN; VARGAS JIMÉNEZ, 2016; COMISIÓN DEL SISTEMA NACIONAL DE CERTIFICACIÓN DE COMPETENCIAS LABORALES, 2015), confirmam a afırmação anterior. Nesses estudos, empregadores identificam trabalho em equipe, comunicação assertiva, aprendizagem ao longo da vida, autonomia, capacidade de adaptação e resolução de conflitos como competências essenciais que faltam à força de trabalho em geral.

É importante notar que os sistemas de EP não são inteiramente responsáveis pela atual lacuna de competências. A região sofre de graves déficits de competências básicas que deveriam ter sido adquiridas antes de o aluno entrar no sistema EP (BUSSO; AMBRUS, 2016). Por outro lado, muitas vezes, o ensino superior oferece aprendizagem de qualidade duvidosa (CASTRO; NAVARRO, 2017). Por fim, as empresas nem sempre conseguem alocar as competências apropriadas para cada cargo (OCDE, 2018).

\subsection{Competências para o futuro, agora}

Em 2016, a OIT/Cinterfor realizou um estudo visando à identificação de competências necessárias para o futuro do trabalho, a fim de informar às suas instituições filiadas (CINTERFOR, 2016). Nesse processo, relatórios do BID, do Fórum Econômico Mundial (FEM), da OCDE, da EIU e da parceria para a aprendizagem do século XXI (P21) foram analisados e sistematizados.

O estudo identificou cerca de 40 competências distintas, que se alinham com as identificadas por INA e Chilevalora. Para fins deste relatório, comparando os conjuntos de definições nos dois quadros a seguir, possibilita-se descrever como essas competências exigidas no futuro fazem parte daquelas indicadas por INA e Chilevalora. 


Quadro 1 - Correlação entre competências socioemocionais para o futuro do trabalho e aquelas
identificadas pelo INA \begin{tabular}{|l|l|}
\hline INA & BID + FEM + OCDE + ElU + P21 \\
\hline Trabalho em equipe & $\begin{array}{l}\text { Colaboração + comunicação + tomada de } \\
\text { decisão, inteligência emocional, negociação, } \\
\text { orientação de serviços, responsabilidade pessoal }\end{array}$ \\
\hline Autonomia & $\begin{array}{l}\text { Responsabilidade pessoal, pesquisa, resolução de } \\
\text { problemas, raciocínio crítico }\end{array}$ \\
\hline Comunicação assertiva & Comunicação \\
\hline Desenvolvimento de relacionamento & $\begin{array}{l}\text { Vida e carreira, cidadania local e global, } \\
\text { comunicação, colaboração, raciocínio crítico }\end{array}$ \\
\hline Profissionalismo & Responsabilidade pessoal, orientação de serviço \\
\hline Resolução de conflitos & $\begin{array}{l}\text { Comunicação, inteligência emocional, } \\
\text { negociação, responsabilidade social, raciocínio } \\
\text { crítico, gestão de pessoas }\end{array}$ \\
\hline Disposição & Responsabilidade pessoal, vida e carreira \\
\hline Adaptabilidade & $\begin{array}{l}\text { Adaptabilidade, raciocínio crítico, flexibilidade } \\
\text { cognitiva, pesquisa, criatividade e inovação }\end{array}$ \\
\hline Orientação para a qualidade & $\begin{array}{l}\text { Produtividade, responsabilidade pessoal, } \\
\text { criatividade e inovação }\end{array}$ \\
\hline Aprendizagem contínua & $\begin{array}{l}\text { Aprendendo a aprender, metacognição, raciocínio } \\
\text { crítico, flexibilidade cognitiva }\end{array}$ \\
\hline Liderança & $\begin{array}{l}\text { Gestão de pessoas, comunicação, tomada de } \\
\text { decisão, inteligência emocional }\end{array}$ \\
\hline Gestão de recursos & $\begin{array}{l}\text { Conhecimentos financeiros e econômicos, } \\
\text { produtividade, gestão de pessoas, } \\
\text { responsabilidade pessoal, consciência ambiental }\end{array}$ \\
\hline
\end{tabular}

Fonte: Elaborado pelo autor.

Quadro 2 - Correlação entre competências socioemocionais para o futuro do trabalho e aquelas identificadas pelo Chilevalora

\begin{tabular}{|l|l|}
\hline Chilevalora & BID + FEM + OCDE + EIU + P21 \\
\hline Comunicação & Comunicação \\
\hline Trabalho em equipe & $\begin{array}{l}\text { Colaboração + comunicação + tomada de decisão, } \\
\text { inteligência emocional, negociação, orientação de serviços, } \\
\text { responsabilidade pessoal, cidadania local e global }\end{array}$ \\
\hline Resolução de problemas & Pesquisa, raciocínio crítico, criatividade, inovação \\
\hline $\begin{array}{l}\text { Aprendizagem contínua } \\
\text { e iniciativa }\end{array}$ & $\begin{array}{l}\text { Adaptabilidade, aprendendo a aprender, metacognição, } \\
\text { raciocínio crítico, flexibilidade cognitiva, criatividade e } \\
\text { inovação }\end{array}$ \\
\hline Eficácia pessoal & $\begin{array}{l}\text { Responsabilidade pessoal, orientação de serviços, tomada } \\
\text { de decisão }\end{array}$ \\
\hline Segurança e cuidado próprio & Responsabilidade pessoal e social \\
\hline
\end{tabular}

Fonte: Elaborado pelo autor. 
Mesmo se houvesse interpretações ligeiramente diferentes para estas definições: comunicação, colaboração, adaptabilidade, aprendizagem contínua, raciocínio crítico, criatividade e inovação, responsabilidade pessoal e tomada de decisão; todas aparentam estar em demanda pelo mercado de trabalho de hoje e do futuro.

Sistemas EP devem sistematicamente começar a desenvolver essas competências. O mercado de trabalho precisa delas e, considerando que os alunos de 15 anos de idade da EP terão 27 anos em 2030, se é que a região pretende aproveitar-se desse bônus demográfico (INTERNATIONAL LABOUR OFFICE, 2013), eles necessitam estar habilitados com essas competências até lá.

\subsection{Ensino e aprendizagem não são a mesma coisa}

Outra inovação

que ajudaria

a redução

da lacuna de

competências

da região são

os PAs
Os sistemas EP na região têm demorado a reconhecer esse novo cenário, provavelmente, porque as empresas só recentemente começaram a perceber o valor das competências socioemocionais. Isso aliviou a pressão pela introdução de inovações no desenho e na oferta de EP.

Até hoje, a maioria dos projetos de desenho e cumprimento de aprendizagens na região segue as abordagens tradicionais, pelas quais o professor e o conteúdo continuam sendo o foco de instrução. Palestras e avaliação da retenção dos fatos ainda são uma prática generalizada.

Mesmo em treinamento vocacional, no qual o modelo do currículo é baseado em competências, integrando conhecimentos, habilidades e atitudes, as competências socioemocionais tendem a ser ensinadas como tópicos independentes e de conteúdo, enquanto o conhecimento técnico ainda é ensinado no quadro da dicotomia artificial teoria-prática. Mais ainda, o ofício é instruído como módulos independentes, o que limita o desenvolvimento de uma compreensão integrada do futuro ambiente de trabalho, da estrutura e de processos.

Ainda assim, há esperança; um número crescente de IEPs está avaliando novas abordagens para a aprendizagem. O Serviço Nacional de Aprendizagem (Sena) da Colômbia instituiu uma abordagem baseada em projetos para todos os modelos de currículo desde o ano de 2007 (RINCON, 2018). O Serviço Nacional de Aprendizagem Comercial (Senac), no Brasil, introduziu uma abordagem semelhante, que vem sendo aplicada em todos os seus regionais desde 2015. O SNA Educa, no Chile, recentemente, adotou projetos-pilotos de ABP em 15 centros de aprendizagem. 0 Instituto Nacional de Treinamento Técnico-Vocacional (Infotep), na República Dominicana, está iniciando um programa-piloto neste ano (2018), e, em 2014, o Instituto Técnico de Treinamento e Produtividade (Intecap), na Guatemala, iniciou a ABP como base metodológica para o desenvolvimento de aprendizagem significativa.

Outra inovação que ajudaria a redução da lacuna de competências da região são os PAs. A região dispõe de várias políticas legislativas de longa data sobre os contratos de aprendizagem, as quais atestam o interesse nos sistemas EP nessa abordagem. 
No entanto, na maior parte da LAC, mesmo em países com sistemas de EP consistentes, como Brasil, Costa Rica e Peru, a penetração da abordagem de aprendizagem é escassa, entre 1\% e 3\% (VARGAS ZUÑIGA; CARZOGLIO, 2017).

Entre as muitas variáveis que ajudam a explicar esses baixos níveis de envolvimento na aprendizagem, estão empreendimentos, cultura dos sindicatos, política laboral do governo, instabilidade macroeconômica e, mais uma vez, falta de entusiasmo para o trabalho que os estudantes da EP tendem a demonstrar.

Tendo em vista esses déficits de competências, a contratação de aprendizes pode tornar-se mais um problema do que um benefício. Esse cenário faz com que muitas empresas se cansem de lidar com aprendizagens. Por exemplo, na Colômbia, onde a lei estabelece o número de aprendizes que as empresas devem contratar, muitos preferem pagar uma multa para cada aprendiz não contratado, em vez de contratar um.

Muitas das condições que impedem a adoção de aprendizes deveriam encontrar respostas adequadas na abordagem de aprendizagem de qualidade OIT/Cinterfor (AXMANN, 2018). Muitas das instituições filiadas estão solicitando cooperação técnica nesse campo. Não obstante, este é o enfoque deste documento. Este relatório visa tão somente analisar o papel das inovações da aprendizagem na diminuição da lacuna em competências que afeta a região.

Em suma, a região ALC vem sofrendo seriamente com a estagnação da produtividade, e uma das causas é a disparidade na oferta e procura de competências. Especificamente, sobre competências socioemocionais, uma razão para esse cenário é que as IEPs ainda dependem de abordagens de aprendizagem tradicionais, que estão infımamente ligadas à realidade do mundo do trabalho, e fazem pouco para compensar os déficits de aprendizagem que os estudantes trazem de suas escolaridades formais anteriores. A fim de transpor esse problema, as IEPs estão testando inovações de ensino, que precisam se tornar predominantes.

\section{Métodos para a redução da lacuna de competências}

Pelo fato de a região ALC apresentar a maior desigualdade no mundo, o acesso à educação de qualidade manteve-se, em grande parte, um privilégio para poucos. Recentemente, o número de estudantes que frequentam a educação formal registrou um aumento notável; no entanto, o impacto nos resultados da aprendizagem tem sido lento (BUSSO; AMBRUS, 2016).

A organização do trabalho tem mudado nos últimos quarenta anos e continuará em transformação, ao exigir novas competências, as quais as abordagens tradicionais de aprendizagem têm, mas não terão a capacidade de oferecer.

Na verdade, é surpreendente que aqueles que se saíram bem utilizando as abordagens de ensino tradicionais sofram com a falta de competências socioemocionais. A incapacidade dos sistemas educacionais para lidarem com mudanças e 
Seria uma perda

de tempo e

esforço educar

e treinar as

gerações mais

jovens por meio

de abordagens

tradicionais proverem aos trabalhadores ferramentas de adaptação e aprendizagem contínua acarretou a necessidade de uma revolução de requalificação (WORLD ECONOMIC FORUM, 2018).

Uma revolução de requalificação pode funcionar para adultos já integrados no mercado de trabalho, mas seria uma perda de tempo e esforço educar e treinar as gerações mais jovens por meio de abordagens tradicionais apenas para descobrir que, algum tempo depois, suas competências estão desatualizadas e há necessidade de uma segunda revolução de qualificação.

O tipo de educação que ontem ajudou a desenvolver adultos bem-sucedidos para o mercado de trabalho e que falhou com eles nesse novo cenário não deveria ser disponibilizada para as gerações mais jovens.

A subseção a seguir se concentrará em duas abordagens de aprendizado: PA e ABP, que, quando aplicadas integralmente, promovem o desenvolvimento das competências socioemocionais exigidas.

\subsection{Qual é o significado dos Programas de Aprendizagem?}

Os Programas de Aprendizagem são uma forma ímpar de educação/formação profissional, combinando formação no local de trabalho e aprendizagem escolar, para competências especificamente definidas e processos de trabalho. São regulados por lei e baseiam-se em um contrato de trabalho formal com pagamento compensatório e cobertura-padrão de proteção social. Uma avaliação formal e uma certificação reconhecida se dão na conclusão de um período de treinamento claramente definido. As aprendizagens combinam: (a) aquisição de experiências profissionais que são diretamente aplicáveis nos locais de trabalho; e (b) aprendizado de conhecimentos aplicados e competências que permitam aos aprendizes entender a lógica por trás dos trabalhos que lhes foram incumbidos, lidar com situações imprevisíveis e adquirir habilidades transferíveis e de níveis superiores.

Outros programas baseados no trabalho apresentam algumas, mas não todas, características da aprendizagem, especialmente duração, avaliação e certificação (ver Quadro 3). 
Quadro 3 - Atributos dos PAs e outros treinamentos efetuados no local de trabalho

\begin{tabular}{|l|l|l|l|l|l|l|l|l|}
\hline & Salário & $\begin{array}{l}\text { Enquadramento } \\
\text { legislativo }\end{array}$ & PA & $\begin{array}{l}\text { Treinamento } \\
\text { fora do } \\
\text { trabalho }\end{array}$ & $\begin{array}{l}\text { Previdência } \\
\text { Social }\end{array}$ & $\begin{array}{l}\text { Avaliação } \\
\text { formal }\end{array}$ & $\begin{array}{l}\text { Certificação } \\
\text { reconhecida }\end{array}$ & Duração \\
\hline $\begin{array}{l}\text { Treinamento } \\
\text { profissional }\end{array}$ & Possível & Não & Não & Não & Sim & Não & Não & $\begin{array}{l}12-24 \\
\text { meses }\end{array}$ \\
\hline $\begin{array}{l}\text { Estágio } \\
\text { profissional }\end{array}$ & Possível & Não & Não & Não* & Não & Não & Não & $\begin{array}{l}3-6 \\
\text { meses }\end{array}$ \\
\hline $\begin{array}{l}\text { Aprendizagem } \\
\text { informal }\end{array}$ & $\begin{array}{l}\text { Dinheiro } \\
\text { para } \\
\text { despesas/ } \\
\text { em } \\
\text { espécie }\end{array}$ & Não & Não & Não & Não & Não & Não & Variável \\
\hline $\begin{array}{l}\text { Trainee } \\
\text { industrial }\end{array}$ & Sim & Possível & Possível & Não & Possível & Não & Não & \\
\hline PA & Sim & Sim & Sim & Sim & Sim & Sim & Sim & $\begin{array}{l}\text { Fixa, } \\
\text { anos }\end{array}$ \\
\hline
\end{tabular}

Fonte: Adaptado da OIT (INTERNATIONAL LABOUR OFFICE, 2012).

*Alguns estagiários estão estudando em universidades/escolas de pós-graduação ao mesmo tempo que estagiam.

Apesar das claras vantagens das qualidades do PA - conforme mostrado no Quadro 3, que as tornam "Padrão Ouro" no ensino e formação profissional - ainda há melindres contra a aprendizagem, que podem ser resumidos nos três pontos duvidosos a seguir:

Mito 1: Aprendizagens são apenas para as economias avançadas

Áustria, Dinamarca, Alemanha, Suíça e alguns outros países europeus, assim como a Austrália, são conhecidos por tradições consolidadas de aprendizagens. Pode assim parecer que somente economias avançadas são capazes de implementar estruturas de aprendizagens. Claro que não é verdade, como pode ser visto claramente a partir dos componentes essenciais de aprendizagens de qualidade no conjunto de ferramentas. Na realidade, a OIT/Cinterfor está apoiando muitas iniciativas de PA em países de média renda, como Brasil, Costa Rica, Jamaica e México, assim como em alguns países de baixa renda, como a República Dominicana.

Mito 2: Aprendizagens são somente para homens

Aprendizagens são associadas com profissões tradicionalmente dominadas por homens (por exemplo, técnicos, carpinteiros e encanadores). Na realidade, a aprendizagem tem oferta em uma faixa ampla de campos, como agricultura, manufatura, finanças, administração de negócios, direito, mídia e saúde, e muitas mulheres jovens participam de PAs. As estatísticas mostram que aproximadamente metade dos aprendizes na Dinamarca e no Reino Unido são do sexo feminino. A porcentagem de aprendizes do sexo feminino é superior a 40\% na Alemanha, na Indonésia, na Itália e na Suíça (INTERNATIONAL LABOUR OFFICE, 2012). 
Mito 3: Somente as grandes empresas podem oferecer PAs formais

Embora possa ser verdade que as grandes empresas têm maior capacidade (mais funcionários que possam orientar aprendizes, maior orçamento para treinamentos, equipamentos mais modernos) para oferecer colocações de aprendiz, pequenas e médias empresas (PME) não hesitam em oferecer PAs. De fato, a grande maioria dos PAs é oferecida por PMEs, por exemplo, na Áustria, na Alemanha e na Suíça. As PMEs unem forças com escolas locais e aceitam os aprendizes. Uma política de apoio às PMEs é imprescindível.

\subsubsection{Os benefícios da aprendizagem}

Como se vê, os benefícios da aprendizagem são múltiplos e se acumulam para todas as partes interessadas:

\section{- Favorece a transição da vida escolar para o trabalho}

Obter o primeiro emprego pode ser muito desafiador para os jovens. Uma razão para isso é que os empregadores, não só na LAC, relutam em contratar jovens cuja produtividade é desconhecida, porque é difícil para eles apreenderem plenamente as competências técnicas e socioemocionais de jovens candidatos a emprego durante o processo de seleção.

Os Programas de Aprendizagem permitem aos empregadores treinar os trabalhadores de que sua empresa necessita enquanto os aprendizes têm a oportunidade de demonstrar seu potencial de produtividade para os empregadores, bem como fazer escolhas bem-informadas sobre educação e formação.

\section{- É um bom negócio}

As empresas investem em aprendizagem porque é um negócio sólido; uma força de trabalho qualificada aumenta a produtividade (LERMAN, 2014). Os benefícios acumulados para as empresas superam de longe os desafios iniciais dos novos aprendizes que precisam de maior supervisão e orientação. As empresas recuperam os custos de treinamento e acumulam benefícios líquidos à medida que aprendizes aprendem o ofício e tornam-se produtivos. Fundamentalmente, empresas também podem economizar custos de recrutamento, já que aprendizes apresentam menores taxas de rotatividade.

\section{- Fornece formação profissional com rentabilidade}

Finalmente, os custos e empenho necessários para que as instituições de treinamento alcancem as tecnologias em aceleração e a demanda de competências dinâmicas são expressivos. Antecipar necessidades futuras de competências, equipando escolas profissionais e centros de formação com instalações e ferramentas mais modernas, atualizando currículos e módulos de formação, assim como requalificando instrutores, naturalmente, inflaciona os custos. As parcerias entre a instituição de formação e a indústria permitem que a primeira utilize os recursos 
das empresas (por exemplo, equipamentos e instalações, conhecimento adquirido) e que a segunda também possa se beneficiar, conforme já discutido. Os agentes governamentais encarregados do ensino e treinamento vocacional podem desejar explorar as oportunidades de utilizar os recursos existentes antes de iniciar reformas dispendiosas dos setores EP na América Latina.

\section{- Reduz a lacuna de competências por meio de ação direta e do efeito de trans- bordamento}

Os esquemas de aprendizagem são um meio sistemático de forjar a colaboração entre os prestadores de EP e a indústria. Os empregadores são muitas vezes críticos das competências dos candidatos ao emprego, atribuindo-as à incompatibilidade entre o ensino e suas necessidades. A fim de ajudar a garantir que os novos aprendizes estejam "prontos para o trabalho", as empresas precisam estar muito mais ativamente envolvidas no treinamento, de preferência, por meio da colaboração com instituições locais de educação/treinamento envolvidas na elaboração e observância de módulos curriculares de treinamento.

0 aprendiz tem um vasto leque de competências socioemocionais
Dada a alta taxa de aprendizes que permanecem na empresa após o término do aprendizado, parece claro que, para essas empresas e aprendizes, a lacuna de competências (específicas e socioemocionais) foi significativamente reduzida. Logicamente, revelando que um forte estímulo na aprendizagem naturalmente ajudaria a reduzir as disparidades de competências.

Além disso, aprendizagens exigem aprendizes que estão amadurecidos o suficiente (VAN BUER, 2013) para realmente beneficiarem-se desse tipo de programa. Estar pronto para a aprendizagem sugere que o aprendiz tem um vasto leque de competências socioemocionais, que devem ser desenvolvidas por processos de pré-aprendizagem ou pelo sistema EP.

Aprendizagens de qualidade são mecanismos que sistematicamente unem educação e instituições de formação e indústria, reduzindo lacunas de competências e qualificações.

\subsection{Aprendizagem Baseada em Projetos}

A Aprendizagem Baseada em Projetos (ABP) é uma forma de Aprendizagem Baseada em Investigação (ABI), uma abordagem que tem por fim levar os alunos a construir seus próprios conhecimentos por intermédio da investigação e observação (OGUZ-UNVER; ARABACIOĞLU, 2014). Além dessas estratégias, em ABP o aluno aprende por meio de um processo de análise, planejamento, desenvolvimento e teste de uma solução para um problema do mundo real. Datada do início do século XX, só ganhou impulso durante a década de 1970 em países do centro e do Norte da Europa (KNOLL, 1997).

A ABP é uma ferramenta formal para colocar em prática muitos dos benefícios que o construtivismo traz para a aprendizagem. Muitos teóricos da pedagogia america- 
na, como Merrill, Jonassen e Kolb, também têm se alinhado com os princípios de trabalho por projetos (JONASSEN, 1999; KOLB, 1984; MERRILL, 2002).

Embora seja difícil apresentar apenas uma definição do que ABP significa, suas principais características são:

- Os alunos são desafiados por um problema de condução para o qual precisam encontrar uma solução.

- $\quad$ O problema em questão deve ser real e exige uma resposta real.

- Os alunos devem realizar pesquisas para entender o problema e criar soluções.

- Os alunos organizam e programam suas próprias atividades até certo ponto.

Outros segmentos de ABP acrescentaram de forma bastante consistente as seguintes características:

- $\quad$ Projetos são realizados por grupos de alunos, e não individualmente.

- Em cursos e programas ligados a negócios e carreiras, os projetos devem seguir etapas e métodos utilizados pelo setor.

- Agentes, de fora do processo de aprendizagem e experientes no ofício, devem frequentemente avaliar o avanço do projeto e os resultados.

Mesmo que haja pouca pesquisa formal antes da década de 1990 e que sua qualidade seja muito heterogênea, resultados confirmam a tese de que a $A B I$ seja mais eficaz para o desenvolvimento de competências socioemocionais (THOMAS, 2000).

Evidências mais concretas em relação à efetividade são provenientes de pesquisas que confirmam que a aprendizagem ativa e significativa é mais eficaz do que a abordagem teórico-prática tradicional por meio de palestras (PRINCE, 2004).

\subsubsection{Benefícios relacionados às competências socioemocionais da $A B P$}

Os alunos desenvolvem competências de comunicação e colaboração por meio do trabalho em equipe, apresentando resultados e, em conjunto, avaliando projeto e processo de aprendizagem. Também devem interagir com pessoas e funções fora do processo de aprendizagem em que exercitam competências de comunicação de acordo com o interlocutor e o contexto. Podem até mesmo enfrentar a necessidade de colaborar com o cliente, a fim de melhor estabelecer o problema em questão e receber uma avaliação sobre seu progresso.

Competências de raciocínio crítico se exercem pela necessidade de pesquisar e contrastar informações, validando as fontes de informação e avaliando o trabalho de seus colegas. Os alunos também avaliam os resultados do seu trabalho em relação às decisões tomadas anteriormente, assim praticando a análise de causa-efeito. Também devem entender as diversas variáveis que afetam seu campo de trabalho e/ou setor produtivo.

A criatividade é uma necessidade para a resolução de problemas. Essas habilidades se desenvolvem por meio de análise de contexto, concepção e implementação 
de soluções para problemas reais relacionados ao ofício, bem como para problemas técnicos e de gerenciamento de projetos em menor escala durante o percurso. Uma questão continua em aberto, no entanto. Como a ABP é melhor que os projetos tradicionais no desenvolvimento de competências socioemocionais? Os alunos não irão espontaneamente desenvolver essas competências socioemocionais, a não ser aprendendo modelos de formação de professores.

A ABP cria oportunidades didáticas para desenvolvimento do raciocínio crítico, comunicação, colaboração e resolução de problemas, por meio de atividades de pesquisa, reflexão, trabalho em equipe e tomada de decisão. No entanto, essas atividades precisam ser projetadas com cuidado e contam com professores que metodologicamente são capazes de oferecer suporte.

Esta seção compartilhou descrições rápidas e os benefícios que as abordagens sugeridas trariam para lidar com a lacuna de competências socioemocionais. 0 próximo passo será discutir algumas questões e uma estratégia para o processo de integração de ambas as inovações nos sistemas EP na região.

\section{Como proceder para integrar PA e ABP em EP}

Dado que ambas as abordagens descritas (PA e ABP) ajudariam a diminuir a lacuna de competências socioemocionais, como os sistemas de EP deveriam integrá-los na região? Além disso, haveria desafios para sua aplicação conjunta?

Como antes mencionado, muitas instituições já começaram a avaliar essas inovações. No entanto, mesmo com variações, a resistência interna foi identificada em toda a parte. IEPs devem integrar essas abordagens em etapas, o que deve ajudar a quebrar a resistência, demonstrando seus benefícios e as mudanças organizacionais necessárias para uma implementação bem-sucedida. Uma sequência sugerida de etapas para uma das instituições filiadas da Cinterfor na América Central é a seguinte:

Etapa 1: Na procura por uma empresa específica ou setor, IEPs devem estabelecer um acordo específico que siga a abordagem PA. Empresas devem ser aquelas que solicitam o PA, e as IEPs devem garantir que todos os parceiros sociais estejam engajados para que o diálogo social possa acontecer e fornecer a fundamentação para a construção do processo pedagógico. IEPs devem realizar essas iniciativas como programas diferenciados dos demais no sistema EP, assim obtendo menor atenção e resistência ao status quo do sistema.

Etapa 2: A iniciativa PA exigirá empenhos específicos de pré-aprendizagem, além de sua experiência EP, para que os futuros aprendizes possam nivelar em matemática e linguagem, bem como desenvolver as competências socioemocionais necessárias para estarem prontos para a aprendizagem. Esses empenhos devem incluir uma abordagem de ABP, a qual, como visto, é a mais eficaz para o desenvolvimento de competências socioemocionais. 
Se essa fase for executada integralmente, as empresas irão reconhecer que, em termos de competências socioemocionais, trabalhadores provenientes do mercado de trabalho ou do sistema EP são mais bem preparados. Assim, a IEP deve deixar claro que isso acontece graças à abordagem de aprendizagem utilizada nos empenhos de pré-aprendizagem.

Etapa 3: Durante a fase anterior, a instituição já teria desenvolvido especialização em treinamento de ABP, bem como PA apoiado por ABP. Nesse momento, a IEP deve investir na construção de um núcleo "ABP + equipe pedagógica PA" e na montagem de um modelo efetivo de treinamento para os treinadores.

A infraestrutura geral e as carências administrativas e de treinamento de professores também teriam sido identificadas, e esse conhecimento deveria ser integrado a um guia de documentos de gestão de mudanças. A equipe administrativa encarregada deve estar em conformidade com uma segunda equipe de gerenciamento de mudanças "PA + ABP". Ambas as equipes e modelos efetivos de treinamento são a base para o objetivo final da abordagem "PA+ ABP".

Etapa 4: A integração ocorre por intermédio da formação de treinadores e de intervenções institucionais destinadas a ajustar as condições administrativas e de infraestrutura. A fım de apoiar esse processo, a instituição deve realizar ofıcinas nas quais os professores e planejadores educativos desenvolvam intervenções ABP, tendo em mente os modelos curriculares e perfis de competência, fornecendo uma base contínua de conhecimento de projetos e plano de curso e treinamento, além de apresentar relatório dos resultados da metodologia.

O Cinterfor sugeriu essas etapas para uma instituição específica, em um momento específico, e pode, assim, estar sujeito a mudanças, dependendo de uma análise mais contextual. A estrutura em geral é, no entanto, aquela em que todos os agentes relevantes de um sistema EP da ALC participariam antes de tentar implementar mudanças de tal grandeza.

Por meio desse processo, os empregadores estariam de acordo, em razão de seu interesse, em melhorar e tornar mais eficaz o mercado de trabalho. Os sindicatos e o governo estariam de acordo, por suas obrigações naturais com o trabalhador/ estudante e com produtividade e desenvolvimento, no quadro do diálogo social construtivo. Uma vez que as três partes que compõem o conselho da instituição estiverem alinhadas com essas mudanças, resistências institucionais podem ser enfrentadas.

Existem situações em que as instituições estão mais abertas às mudanças, ou em que a abordagem dedutiva pode ser aplicada desde o início. Nesses cenários, que são mais favoráveis para a introdução de inovações, a abordagem do processo de mudança deve ser feita em uma perspectiva de diálogo social, a fım de ser (mais) sustentável. 


\section{Considerações finais}

A lacuna de competências socioemocionais existente na ALC corresponde às lacunas de competências identificadas para 0 mercado de trabalho do futuro
Conforme mencionado anteriormente, a lacuna de competências socioemocionais existente na ALC corresponde às lacunas de competências identificadas para o mercado de trabalho do futuro em nível global. Logicamente, identificar abordagens EP para o fechamento ou estreitamento da presente lacuna de competências da região torna-se o mesmo exercício de procurar ferramentas para estreitar o futuro da lacuna de competências de trabalho.

A análise e o compartilhamento de duas abordagens se provaram eficazes no desenvolvimento de competências socioemocionais. Por um lado, PAs para a transição da escola para o trabalho, pelo outro, ABP para tudo que envolve a EP.

De preferência, as abordagens baseadas em projetos deveriam apoiar aprendizagens de qualidade, ao menos durante os empenhos de pré-aprendizagem, mas provavelmente durante todo o aprendizado. Além disso, seria seguro dizer que as taxas de médio prazo da participação de aprendizes na região não excederão $20 \%$. Caso se esperasse que $80 \%$ dos alunos pudessem exibir as competências socioemocionais apropriadas ao deixar o sistema EP, a ABP deveria ser aplicada em todas as áreas, e não apenas durante as atividades do PA. Portanto, ao menos na região da $L A C$, PAs necessitam de ABP e o mercado de trabalho requer EP para implementar inteiramente ambas as abordagens.

Em 2019, entre outras atividades, o Cinterfor planeja apoiar o Infotep em seus programas-piloto de projeto e implementação de PA e ABP e publicar com o Senac resultados de pesquisas sobre estratégias de instrução de ensino e avaliação de competências socioemocionais. Um livro contendo uma análise regional do uso da ABP na região está também para ser publicado. Além disso, o Cinterfor iniciará o desenvolvimento combinado de um conjunto de ferramentas de implementação de ABP para EP na América Latina.

Mais pesquisas devem ser realizadas, a fim de se compreender pelo menos duas variáveis que dificultam a implementação dessas abordagens no nível de pré-aprendizagem: (1) o efeito do Ensino Baseado em Competências (EBC) no ensino centrado no aluno; e (2) o efeito da rotatividade de professores na sustentabilidade dessas inovações.

\section{Referências}

AXMANN, M. Quality apprenticeships: a practical approach for Latin America and the Caribbean. Montevideo: ILO/Cinterfor, 2018. Forthcoming. 
BUSSO, M.; AMBRUS, S. Latin America, the Caribbean and PISA: the long road ahead. In: IDB. Ideas matter. [S.I.], Dec. 13, 2016. Disponível em: <https://blogs. iadb.org/ideasmatter/2016/12/13/latin-america-the-caribbean-and-pisa-the-longroad-ahead/>. Acesso em: 21 nov. 2018.

CALVO SANTANA, A.; COTO CALDERÓN, J. A.; VARGAS JIMÉNEZ, L.

Capacidades actitudinales por incorporar en la formación profesional basada en competencias laborales del INA. San José: Instituto Nacional de Aprendizaje, 2016.

CASTRO, C. M.; NAVARRO, J. C. Will the invisible hand fix private higher education in Latin America? Ensaio: avaliação e políticas públicas em educação, Rio de Janeiro, v. 25, n. 96, p. 770-797, 2017.

CINTERFOR. El futuro de la formación profesional en América Latina y el Caribe en el SXXI. Montevideo, 2016. Unpublished research report.

COMISIÓN DEL SISTEMA NACIONAL DE CERTIFICACIÓN DE COMPETENCIAS LABORALES (Chile). Catálogo de competencias transversales para la empleabilidad. Santiago: Chilevalora: Sence, 2015.

ECLAC. Structural change for equality: an integrated approach to development: Thirty-Fourth Session of ECLAC. San Salvador: Eclac, 2012.

INTERNATIONAL LABOUR OFFICE. Employment and social protection in the new demographic context. Geneva: ILO, Apr. 2013.

INTERNATIONAL LABOUR OFFICE. Overview of apprenticeship systems and issues: ILO contribution to the G 20 task force on employment. Geneva: ILO, Nov. 2012.

JONASSEN, D. Designing constructivist learning environments. InstructionalDesign Theories and Models, [s.I.], v. 2, p. 215-239, 1999.

KNOLL, M. The project method: its vocational education origin and international development. Journal of Industrial Teacher Education, Blacksburg, VA, v. 34, n. 3, p. 59-80, Spring 1997.

KOLB, D. A. Experiential learning: experience as the source of learning and development. Englewood Cliffs: Prentice Hall, 1984. p. 20-38. 
LERMAN, R. Do firms benefit from apprenticeship investments? IZA World of Labour, Bonn, May 2014.

MELGUIZO, Á; PEREA, J. Mind the skills gap!: regional and industry patterns in emerging economies. Paris: OECD Publ., 2016. (OECD Development Centre Working Papers, n. 329).

MERRILL, M. D. First principles of instruction. Educational Technology Research and Development, Heidelberg, v. 50, n. 3, p. 43-59, 2002.

OECD. Getting skills right: Chile. Paris: OECD Publ., 2018.

OGUZ-UNVER, A.; ARABACIOĞLU, S. A comparison of inquiry-based learning $(\mathrm{IBL})$, problem-based learning $(\mathrm{PBL})$ and project-based learning $(\mathrm{PJBL})$ in science education. Academia Journal of Educational Research, v. 2, n. 7, p. 120-128, July 2014.

PRINCE, M. Does active learning work?: a review of the research. Journal of Engineering Education, v. 93, n. 3, p. 223-231, 2004.

RINCON, H. Pasado, presente y futuro de la formación pasada en proyectos en el SENA. Bogotá: Sena, 2018.

SALAZAR-XIRINACHS, J. M.; VARGAS ZÚÑIGA, F. The future of vocational training in Latin America and the Caribbean: overview and strengthening guidelines.

Montevideo: OIT/Cinterfor, 2017.

THOMAS, J. W. A review of research on project-based learning. San Rafael, CA: Autodesk Foundation, 2000.

VAN BUER, J. Transdisciplinary skills: new perspectives for old virtues between acquisition of skills and profession. 2013. Conference presentation.

VARGAS ZUÑIGA, F.; CARZOGLIO, L. La brecha de habilidades en América Latina: desencuentros y hallazgos. Montevideo: Ol/Cinterfor, 2017.

WORLD ECONOMIC FORUM. Towards a reskilling revolution: the future of jobs for all. In collaboration with The Boston Consulting Group. Geneva: World Economic Forum, Jan. 2018. 